\title{
What Quine (and Carnap) might say about contemporary metaphysics of time
}

\author{
Natalja Deng
}

\begin{abstract}
This chapter explores some of the relations between Quine's and Carnap's metaontological stances on the one hand, and contemporary work in the metaphysics of time on the other. Contemporary metaphysics of time, like analytic metaphysics in general, grew out of the revival of the discipline that Quine's critique of the logical empiricists (such as Carnap) made possible. At the same time, the metaphysics of time has, in some respects, strayed far from its Quinean roots. This chapter examines some likely Quinean and Carnapian reactions to elements of the contemporary scene.
\end{abstract}

\section{Introduction}

The aim of this chapter is to examine the reactions that Quine and Carnap might have (had) to disputes in contemporary metaphysics of time. Quine is generally taken to be a central figure in the historical development that led to the demise of logical empiricism, and thereby to the rebirth of metaphysics. At the same time, it has been suggested that one ought not to overstate the extent to which contemporary metaphysics can claim to be Quinean in spirit, nor to understate matters on which Quine and Carnap were in fact united. Contemporary metaphysics of time provides us with an interesting testing ground for some views of Quine's place in the history of philosophy. It is also an area where historical reflection is increasingly welcome and much needed, so the exercise may be mutually beneficial.

The structure of the chapter is as follows. Section two outlines the central elements of Quine's metaontology, as well as key ontological and background commitments of Quine's that are relevant to temporal metaphysics. Section three contrasts this with the Carnapian metaontology of 'Empiricism, Semantics and Ontology', and describes Quine's critique of Carnap. Section four then highlights some ways in which contemporary temporal metaphysics is no longer Quinean in spirit, even though much of it has been presented as a continuation of a broadly Quinean program. Finally, section five reviews some recent challenges to the substantivity of some debates in temporal metaphysics and situates both Carnap and Quine with respect to these challenges.

\section{Quine, Metaontology and the Spatiotemporal View of Nature}

Quine's metaontological stance is often summed up in the slogan 'to be is to be the value of a [bound] variable' (Quine 1948, 34). What is being summed up here is a general method for deciding what your theories commit you to- a way of determining what you should believe there is, given your best theory. That method is as follows. Take this best theory and reformulate it in the clearest and simplest possible form. In particular, regiment the sentences of the theory by symbolizing them in the language of firstorder predicate logic with identity. Then, check what the variables of the sentences of this regimented theory range over, and commit yourself to all and only the entities needed to stand in as the values of 
bound variables in order to make the sentences of the regimented theory true. You should think that there are all and only those things.

One important element of this metaontological outlook is that it generally does not distinguish between claims to the effect that some entities exist and claims to the effect that there are such entities. Being is existence; there are no things that do not exist $]^{1}$ A related element of the Quinean approach to metaontology is that no distinctions are made between different modes or kinds or degrees of existence. A thing either exists or it does not, and tables and chairs exist in just the same sense as sets do.

Quine distinguishes between what he takes to be two equally philosophically interesting aspects of theories: ontology and ideology. What we have just seen is his method for finding out about a theory's ontology, that is, what the theory says there is: 'what entities are the variables of quantification to range over if the theory is to hold true?' (Quine 1951a, 14). Ideology, on the other hand, is a matter of what ideas can be expressed in the language of a theory, or what sorts of predicates are to be admitted as primitive. In 'Ontology and Ideology' (1951a), Quine expresses some misgivings about the question of ideology. He says there that while both the ideology and the ontology of a theory are a matter of semantics, they belong to different parts of semantics. Ontology belongs to the theory of reference, while ideology tends to fall within the theory of meaning. The theory of reference deals with naming, denotation, extension, coextensiveness, values of variables, and truth, while the theory of meaning deals with, by Quinean lights, rather less clear things like synonymy, analyticity, syntheticity, entailment and intension. Thus, in 'Ontology and Ideology', Quine suggests that the question of the ideology of a theory often inherits many of the difficulties that beset these latter notions: it is 'heir to the miserable conditions, the virtual lack of scientific conceptualization, which characterize the theory of meaning.' However, 'a partial analogue of the theory of meaning is contained within the theory of reference itself; here extension takes the place of intension, coextensiveness of predicates takes the place of synonymy of predicates, and truth takes the place of analyticity. Much in the way of ideological study can be usefully pursued thus within the theory of reference' (Quine 1951a, 15).

In any case, Quine's mature view is that there is nothing wrong with the question of ideology per se, but that only some kinds of ideology are problematic. In particular, the kinds of ideology that fall within the theory of meaning (meaning, analyticity, intension, synonymy) are problematic, while ideology such as predicates and truth-functions, which fall within the theory of reference, are acceptable.

Another relevant background commitment is Quine's inclination to refrain from positing facts. In Word and Object, Quine explains why he takes the tendency to posit facts as objects to be as misguided the tendency to posit propositions. Both stem from a 'tendency to be carried-away by object-directed thinking' (Quine 1960, 245), and neither is in any way helpful. The tendency to posit facts is also, according to Quine, partly motivated by the wish to defer the question of what actually makes a sentence or proposition true, by saying instead that all and only those that are true state facts. Moreover, the 'disarmingly commonplace ring' of the term 'fact' lends 'spurious intelligibility' to the analytic-synthetic distinction (and worse, to that distinction when it is used in an implausibly absolute sense, apparently independent of a choice of language): synthetic truths are sometimes said to be those to which there are corresponding facts, while analytic truths are said to be those without factual content. Quine's critique of the analytic-synthetic distinction, so central to his exchanges with Carnap, thus makes him further inclined to refrain from positing facts.

Quine's ontological commitments with respect to time are evident in various places (Quine 1939, 1950, 1953, 1960). Quine takes a 'four-dimensional spatio-temporal view of nature' (Quine 1939, 701). Just as one would expect given his metaontological method, this is directly connected to a view about how temporal information is best treated by the canonical language into which we should regiment our

\footnotetext{
${ }^{1}$ It is interesting to note, however, that while Quine sometimes says that the existential quantifier is closely related to the use of 'there is' in ordinary language, in other places he suggests instead that there is more distance between the two (Janssen-Lauret 2015, 150): 'Ontological concern is not a correction of a lay thought and practice; it is foreign to the lay culture, though an outgrowth of it' (Quine 1981, 9).
} 
theories. Partly for reasons having to do with elegance and theoretical simplicity, that canonical language is a tenseless one. In a tenseless language, 'I will not do it again' becomes 'I do not do it after now', where the 'do' is tenseless—or as Quine also says, timeless—-that is, it doesn't convey temporal information. The future force of 'will' is translated into 'after now', 'comparable to "west of here"'(Quine 1960, 169). This, Quine argues, is already beneficial just within the domain of logic (though Quine also emphasizes other benefits, such as fit with relativity theory—see below).

Take, for instance, the inference from 'seven of them remained and seven is an odd number' to 'an odd number of them remained'. One intuitively takes this to be valid. By contrast, from 'George married Mary and Mary is a widow' one does not want to and should not infer 'George married a widow'. Dropping the tenses makes explicit why the first inference is valid while the second one is not. The first one becomes 'Seven of them then remain and seven is an odd number; therefore an odd number of them then remain'. By contrast, from 'George marries before now Mary and Mary is a widow now', one should not infer 'George marries before now (one who is then) a widow', but rather 'George marries before now (one who is) a widow now'. A tenseless canonical language makes this explicit and therefore lays such inferences 'conveniently open to logical inspection' (Quine 1960, 169).

Quine expresses this point in no uncertain terms in his review of Strawson's Introduction to Logical Theory (Strawson 1952):

The only tenable attitude toward quantifiers and other notations of modern logic is to construe them always, in all contexts, as timeless. ... The four-dimensional view of space-time is part and parcel of the use of modern formal logic, and in particular the use of quantification theory, in application to temporal affairs. ... It would be hard to exaggerate the importance of recognizing the tenselessness of quantification over temporal entities. ... I see no reason to expect a coherent application of quantification theory to temporal matters on any other basis. ... I do not see how, failing to appreciate the tenselessness of quantification over temporal entities, one could reasonably take modern logic very seriously. (Quine 1953, 442-443)

As mentioned, a separate benefit of a tenseless canonical language emphasized by Quine is the fit with relativity theory. He says that relativity theory really leaves us no alternative but to treat time as on a par with space in the way reflected in a tenseless language, since in that theory space and time turn out to be 'distinguishable only relative to a velocity'. But this, for Quine, is a separate benefit, one that confirms what we already knew to be the superior way of treating temporal information.

All this is then extended by Quine to a particular view about the existence of physical objects in time (in modern terms, about persistence). The spatiotemporal view of nature, as Quine understands it, not only treats time as on a par with space in the sense reflected in a tenseless language, but also treats physical objects as spatiotemporally extended. In fact, it treats physical objects as themselves events, or processes. 'Physical objects, conceived thus four-dimensionally in space-time, are not to be distinguished from events or, in the concrete sense of the term, processes' (Quine 1960, 170). Both are the contents of portions of space-time.

Thus, time and space are to be treated as on a par, in both our view of the nature of time and of objects' existence through time. And in the case of persistence too Quine sees welcome additional benefits of the spatiotemporal view, in the form of further dissolution of otherwise puzzling problems. For example, Quine thinks that when we apply it to persons, the spatiotemporal view helps one appreciate why there need be no unchanging kernel of personhood in order to make one's childhood and old age into parts of the same person. No matter how dissimilar these parts are, they still count as parts of one person, just like there need be no 'peculiarly Quinian textural quality common to the protoplasm of my head and feet' (Quine 1960, 170). 


\section{Carnap versus Quine}

Contrast this with the Carnapian stance on ontology. Recall Carnap's 'Empiricism, Semantics and Ontology' (Carnap 1950), in which he makes use of the notion of a 'linguistic framework' and the accompanying distinction between 'internal' and 'external' existence questions: 'If someone wishes to speak in his language about a new kind of entities, he has to introduce a system of new ways of speaking, subject to new rules; we shall call this procedure the construction of a linguistic framework for the new entities in question' (Carnap 1950, 242).

A linguistic framework, says Carnap, is made up of terms and expressions together with rules governing those terms and expressions. For example, the numbers framework consists of the following: number terms such as 'three'; the general term 'number' and sentence forms like 'three is a number'; expressions for properties (e.g. 'prime'), relations (e.g. 'is greater than'), and functions (e.g. 'plus'), and sentence forms like 'two plus three is five'; numerical variables (e.g. 'n'), as well as existential and universal quantifiers governed by the usual deductive rules.

Not all frameworks are consciously constructed; nor are all frameworks of a technical nature. For example, another framework discussed by Carnap is the framework of things and events in spacetime (let's call it the 'things framework'). That framework is adopted by each of us 'early in life as a matter of course'. But the introduction of any framework consists essentially of two steps: the introduction of a general term for the new kind of entities ('number', 'thing'), and the introduction of variables of the new type. The new entities are then values of these variables.

Carnap then introduces the distinction between internal and external questions: 'and now we must distinguish two kinds of questions of existence: first, questions of the existence of certain entities of the new kind within the framework; we shall call them internal questions; and second, questions concerning the existence or reality of the system of entities as a whole, called external questions' (Carnap 1950, 242).

Take, for example, the numbers framework. Examples of internal questions would be 'how much is three plus three?' or 'is there an even prime number?' These are answered with the help of the rules of the framework. Since this framework is a logical one, the method of answering is logical also. In the case of frameworks that are not logical but factual, such as the things framework, internal questions are answered empirically. Thus, examples of questions internal to the things framework would be 'did King Arthur actually live?' or 'is there a white piece of paper on my desk?'

But now consider questions such as 'do numbers exist?' or 'are there physical objects?' According to Carnap, such questions must be interpreted as either internal or external questions. If they are interpreted as internal questions, namely as questions internal to their respective frameworks, they have trivially positive answers. Their answers follow analytically from positive answers to more specific internal questions. Thus, from 'there exists a prime number between three and seven', 'there exist numbers' can be derived, given the rules of the numbers framework. Similarly, from 'there is a white piece of paper on my desk', 'there are physical objects' can be derived, given the rules of the things framework. Such trivial answers indicate that this is not the way in which ontologists asking about the reality of numbers or the external world intend their questions to be interpreted. However, the only other way they could be interpreted is as external questions, and in particular, as external practical questions concerning whether or not we should adopt certain frameworks. Clearly, this is not what ontologists have in mind either: they mean to be asking a non-trivial theoretical question. But, argues Carnap, it is not clear what meaning external questions might be given that would make them theoretical rather than practical. This is why, in Carnap's view, ontological disputes are simply misguided.

As is well known, Quine's response questions the presuppositions on which this metaontological stance rests, most centrally the analytic-synthetic distinction. In 'Carnap's Views on Ontology', Quine starts out by critically examining the distinction between 'internal' and 'external' questions on its own terms. To begin with, Quine suggests that what Carnap is trying to get at with this distinction can be helpfully put as follows. Consider questions of the form 'are there so-and-sos?', where the so-and-sos 
'purport to exhaust the range of a particular style of bound variables, and questions of that same form, where the so-and-sos do not purport to do so' (Quine 1951b, 68-69). Quine calls the former category questions, and the latter subclass questions. External questions would be category questions posed before the adoption of a particular language (or framework). Internal questions would include subclass questions, and also category questions construed as posed after the adoption of a given language, when Carnap wants to treat them as having trivially analytic or contradictory answers. Quine's verdict on the significance of the 'internal'-'external' contrast thus clarified is a negative one. His reason is that whether or not one uses a new style of variable for referring to so-and-sos is not significant, so that whether or not a question is of the 'subclass' or 'category' variety hangs on trivial considerations. 'It is a distinction which is not invariant under logically irrelevant changes of typography' (Quine 1951b, 71).

Quine then moves on to his main criticism, which is that the distinction that is really doing the work in Carnap's approach is the (by Quinean lights, previously discredited) analytic-synthetic distinction. Carnap himself says as much in a footnote (Carnap 1950, fn. 5):

Quine does not acknowledge the distinction which I emphasize above [viz. the distinction between ontological questions and factual questions of existence], because according to his general conception there are no sharp boundary lines between logical and factual truth, between questions of meaning and questions of fact, between the acceptance of a language structure and the acceptance of an assertion formulated in the language.

Without this distinction, no basis remains for distinguishing between the ontologist's existence statements and empirical existence statements. Ontology becomes part of science (Quine 1951b, 72):

Within natural science there is a continuum of gradations, from the statements which report observations to those say of quantum theory or the theory of relativity. The view which I end up with, in [Two Dogmas of Empiricism] is that statements of ontology or even of mathematics and logic form a continuation of this continuum, a continuation which is perhaps yet more remote from observation than are the central principles of quantum theory or relativity. The differences here are in my view differences only in degree and not in kind. Science is a unified structure, and in principle it is the structure as a whole, and not its component statements one by one, that experience confirms or shows to be imperfect. Carnap maintains that ontological questions, and likewise questions of logical or mathematical principle, are questions not of fact but of choosing a convenient conceptual scheme or framework for science; and with this I agree only if the same be conceded for every scientific hypothesis.

\section{Quine Meets Contemporary Temporal Metaphysics}

At the risk of proceeding somewhat anachronistically, suppose we now ask how Quine might react to contemporary debates in the metaphysics of time. In its full generality, that question impossibly demands that one trace the entire historical development from Quine to the contemporary scene. But we can instead focus on some more local points of comparison.

The overall shape of the answer will be this. While Quine's critique of Carnap and the logical empiricists made possible a resurgence of metaphysics, the particular form that contemporary metaphysics takes would in fact often be anathema to Quine. As Peter Hylton points out, '[m]any philosophers have welcomed the freedom to speculate about the nature of the world but have not accepted Quine's constraints on the process' (Hylton 2018). As we have seen, Quine speaks of 'ontology' and 'ideology', and he advances particular ontological views about time and persistence ${ }^{2}$ But methodologically, he is clear in his rejection of a priori (armchair) metaphysics, championing instead a posteriori, empirical methods.

\footnotetext{
${ }^{2}$ Though note that he himself only occasionally uses the term 'metaphysics'. For one occasion, see (Quine 1951a, 13).
} 
And while he thereby also means to salvage what is worth salvaging in previous generations' metaphysical projects (Janssen-Lauret 2015, 4), it is unlikely that all of contemporary metaphysics of time would seem to him worth salvaging.

One fairly standard way of conceiving of the contemporary debate in the metaphysics of time is as a debate about whether time (robustly) passes or flows, or whether it has a dynamic aspect that space lacks. By this metaphysicians of time mean something very specific: is there some metaphysical privilege characterizing one time, which is dynamically transferred from time to time? The notion of a metaphysical privilege is deliberately underspecified here, because many different kinds of privilege have been proposed. One kind is ontological. For example, one time may be the only time that exists or is real, and the passage of time may consist in times going into and going out of existence. Or alternatively, one time may be the latest time that exists, in which case the passage of time consists in new times coming into existence. These views are known as Presentism and the Growing Block View, respectively. A third way of thinking of the passage of time is to take all times to exist but to think of one time as objectively present, in a sense that goes beyond each time being simultaneous with (and hence present at) itself. This way of thinking of the passage of time results in a Moving Spotlight View. Each time becomes less distantly future, then present, and then moves off into the ever more distant past.

Opposed to all three of these is the view that denies that time passes, in any metaphysically robust sense. Time is distinguished from space in various ways, but it does not have this dynamicity, understood as involving a transfer of metaphysical privilege. Each time exists, and each one is present at itself, but that is no more remarkable than that each spatial location is here at itself, so to speak. Similarly, to say that a time is in the past or the future is just to say that it happens earlier or later than the time of speaking.

Let's call the view that denies that time passes the B-theory, and views that include passage Atheoretic views. Presentism, the Growing Block View and the Moving Spotlight View are all A-theoretic views. The B-theory is more uniform.

The 'AB' terminology goes back to J. M. E. McTaggart, the British idealist most famous for arguing that time doesn't exist. For our purposes, what matters is not that argument, but the 'AB' terminology, which is still very commonly used ${ }^{3}$ Think of the events that make up world history. McTaggart noticed that there are two different ways of thinking of this sequence of events, both of which are part of everyday thought and language. The first is to think of the events as being earlier and later than one another. This is the B-series. The second is to think of the events as each being either past, present, or future. This way of thinking results in the A-series_or rather in one A-series of many, since one can think of each event as being present in turn, while all the others are accordingly either past or future.

The difference between the A- and the B-series becomes clearer if one considers which kinds of remarks about time change their truth-value over time. It's always true to say that World War I happened before World War II, or rather that World War I happens (i.e. occurs in world history) before World War II. Here we're stating a so-called tenseless fact, named after the tenseless verb form of 'happens', which does not convey any information about whether these events are in the speaker's past, present, or future. Such tenseless facts do not change over time. They characterize world history once and for all. By contrast, if I say that World War II is about to begin, then I am stating a (purported) tensed fact, one that will (would later) change. Or, to pick an example where the tensed statement in question is true, 'World War II ended 74 years ago.' The tensed fact stated here is one that obtains right now but will change, to be replaced by the fact that WWII ended 75 years ago, and then that it ended 76 years ago, and so on. It's only the A-series that changes in this way, as time (robustly) passes. That is why theories of time according to which time passes are called A-theories, and theories of time on which it does not are called versions of the B-theory ${ }^{4}$

\footnotetext{
${ }^{3}$ Here we can focus just on the 'AB' aspects of McTaggart's terminology, ignoring the ' $\mathrm{C}$ ' aspect, which has played a slightly less central role to date.

${ }^{4}$ Incidentally, the distinction between McTaggart's A- and B-series is echoed in the distinction between deictic time and sequence time, employed in cognitive science and linguistics (Callender 2017).
} 
McTaggart himself raised the question of whether one of the two series is more fundamental than the other. He thought the A-series was more fundamental. This issue is also central to the contemporary debate. Broadly speaking, A-theorists agree with McTaggart that the A-series is more fundamental. Tensed facts, such as that your reading this paragraph is present, cannot be reduced to mere tenseless facts, such as that your reading this paragraph happens at a time later than my writing it. If there is a reduction, it goes the other way: tenseless facts obtain in virtue of tensed ones. The big bang precedes your reading this sentence (a tenseless fact) only because it was present while your reading this was future, and is past while your reading this is present (both tensed facts).

B-theorists, by contrast, think that the B-series is more fundamental. Of course, B-theorists recognize that we use terms like 'past', 'present', and 'future'. But they think of these as being on a par with terms that express spatial perspectives, like 'here', 'over there', or 'on the left'. Just like there is nothing metaphysically significant about the location one is at, even though one can refer to it and no other location as 'here', there is, according to B-theorists, nothing metaphysically significant about the time one is at, even though one can refer to it and no other time as 'now'. At the fundamental level, there are only tenseless facts, such as that the Big Bang precedes your reading this, or that World War I precedes World War II.

What might Quine say about the debate thus conceived? Do Quine's first-order metaphysical commitments on time (and persistence) straightforwardly locate him within one of these two camps, perhaps most saliently the B-theoretic one? Or is there some mismatch between the contemporary B-theory of time and Quine's 'spatiotemporal view of nature'? And if there is, does that mismatch reflect a broader difference between Quine's approach to metaphysics and the contemporary metaphysics scene?

Note that the question is not just whether Quine is able to consider and understand ontologies that are not his own. He certainly takes his metaontological method to be helpful in assessing the ontological commitments of various theories, including ones whose ontologies he rejects, such as realism about propositions, Platonism, theism, or modal realism (Janssen-Lauret 2016). Thus, assuming that he is right about this advantage of his metaontological method, the question can't be whether he is able to consider and understand one, or both, sides of a contemporary dispute about temporal ontology (or about temporal metaphysics). Rather, what we're asking is whether his own first-order commitments on time and persistence make him a supporter of one of these two sides. In particular, the question is how (dis)similar his own stance on time looks from that of a contemporary B-theorist. Again, one reason to be interested in this is that a remaining mismatch might tell us something about a broader difference between Quine and contemporary metaphysicians of time (taking the latter group to be a suitably uniform group for the purposes of this discussion).

As we have seen, Quine declines to posit facts, because he thinks doing so is the result of a misguided tendency to reify where it is not necessary. This may already make one a little uneasy about locating Quine in the 'fundamental tenseless facts' camp. But then again, talk of facts is not essential to the contemporary debate in all its guises. As we have also seen, one can ask, in original McTaggartian terms, whether the A- or B-series of events is fundamental.

Nonetheless, the project of enquiring into a fundamental level of reality does not seem straightforwardly Quinean. Why not? To begin with, one might want to blame the talk of levels of reality. Surely for Quine, for whom the road to ontology leads via the regimentation of our best theories into a canonical tenseless language, this talk of reality as such is suspiciously independent of a choice of language. But suppose we talk instead of what there is, and what it is like, in the terms given by the fundamental language, the language whose expressions carve nature at the joints. The central question in temporal metaphysics then becomes whether or not the shape of nature's temporal joints is tensed or tenseless. Is the debate now Quinean in spirit?

This formulation of the time debate is largely due to Ted Sider. In Sider's terms, the dispute is first and foremost ideological. It is about whether nature's temporal joints have a first-order predicate logic shape (eternalist, B-theorist) or a quantified tense logic shape (presentist, a typical A-theorist). The two 
sides also have ontological disagreements that result from this, because the presentist denies, while the eternalist maintains, that, for example, $\exists x D x$, namely that there exist dinosaurs. Since, for the presentist, $\phi \leftrightarrow N \phi$, for all $\phi$, this would be true only if there presently existed dinosaurs. The presentist denies this and maintains instead that $P \exists x D x$, namely that it was the case in the past that there exist dinosaurs.

In framing the time debate in these terms, Sider claims continuity with the Quinean tradition, broadly speaking (Sider 2011, 16):

The familiar Quinean thought is that we search for the best-simplest, etc.- - theory that explains our evidence. My addition to this thought—-though it may have been implicit all along-is that this search is ideological as well as doctrinal; we search simultaneously for a set of concepts and a theory stated in terms of those concepts. ... Many of the most dramatic advances in science are ideological; a new ideology (such as that of Minkowskian spacetime) can dissolve intractable problems and enable new, more powerful theories.

As we saw in section two, Quine recognizes the question of the ideology of a given theory. And it is clear which side's ideology he would prefer. However, there still seems to be a difference regarding the reasons for which Quine, as opposed to a contemporary Siderean B-theorist, would prefer a B-theoretic ideology. For Quine, the question is whether the best theories we currently have are to be regimented in a tenseless language, with the ideology of first-order predicate logic (rather than one that also includes tense operators), allowing quantification over times that are 'past' and 'future' relative to the time of speaking. Since he answers that question in the affirmative, there is a sense in which for Quine all times exist. But someone following Sider's program is going beyond this in the degree of metaphysical seriousness which motivates their interest in the language of those theories. They are trying to find out about the fundamental structure of reality; they are pursuing metaphysical research into the language in which the book of the world is written (Sider 2011, 9/10):

Realism about structure leads to realism about fundamental languages. There is a privileged way to 'write the book of the world,' a privileged set of concepts one must use in order to conform one's beliefs to the world. ... Do tensed concepts [carve nature at the joints]? ... Phrasing the issue as one about the fundamental 'shape' of reality's temporal joints helps to illuminate what are otherwise extremely perplexing questions. ... Those who think that 'time is like space' say that there is no 'genuine' or 'objective' distinction between past, present, and future, but they do not deny that there once were dinosaurs. ... If 'genuine' and 'objective' are dropped then the position becomes incoherent. These are not merely questions about what is true; they are questions of what is true at the fundamental level.

It is hard to overstate the intended metaphysical depth of these problems. Not only are they intended to be directly relevant to scientific research into the nature of time, but the particular form they take is not themselves dictated by the physical sciences. The driving question in this debate is whether time (robustly) passes, that is, whether it is dynamic in a way space is not. In a way, that question has not really evolved much since Parmenides and Heraclites. The direction of theorizing here runs from metaphysics to physics, not the other way around. This, it seems, is a new note that contemporary metaphysics is striking and that is not present in Quine's outlook.

One might object that this is an unfair portrayal of contemporary metaphysics of time. Is modern physics not usually taken to have shown the A-theory wrong? The conflict between special relativity and the presentism is especially well-documented. Does that not show that the 'direction of theorizing' runs as much from physics to metaphysics as the other way around? There are two things to say in response. First, there is room for doubt about this way of viewing the relation between special relativity and temporal ontology 5 Second, even if special relativity had vindicated eternalism (and the B-theory), it

\footnotetext{
${ }^{5}$ See, e.g., Deng (2018) and references therein.
} 
would still be the case that the driving question in the metaphysics of time is not one to which physicists qua physicists have ever had to give any thought. Whether or not time (robustly) passes is a metaphysical question that is brought to physics from the outside. As Carnap reports (1963, 37-38), Einstein had genuine worries in the vicinity, but that just shows that physicists too engage in metaphysics on occasion:

Once Einstein said that the problem of the Now worried him seriously. He explained that the experience of the Now means something special for man, something essentially different from the past and the future, but that this important difference does not and cannot occur within physics. ... That this experience cannot be grasped by science seems to him a matter of painful but inevitable resignation.

A different objector might point out that Quine rejects Carnap's Principle of Tolerance. According to that principle, while different languages are useful for different purposes, and different languages have different expressive powers, there is no single correct language. Quine rejects this Principle, because it relies on the dogmas he has criticized. For Carnap, the analytic sentences are those meaning-giving sentences that are constitutive of a language. Changing our mind about them does not require theoretical justification. These are 'external', purely practical changes, amounting to the adoption of new languages. The synthetic sentences, on the other hand, are those whose adoption constitute 'internal' changes, which are subject to different epistemological standards. They require evidence. Quine rejects any such distinction, and thus the principle that relies on them. As a result, for Quine, choosing a language is not a different kind of step from choosing to accept a sentence or a theory in that language. Both are potentially affected by pragmatic considerations, for example ones having to do with simplicity.

But, of course, to reject the Principle of Tolerance is not yet to endorse the claim that there is a single correct language, let alone the claim that that language is 'fundamental'.

One can acknowledge the proposed difference between Quine and a contemporary Siderean B-theorist without saddling Quine with an inability to distinguish between truth and usefulness. Janssen-Lauret $(2015,4)$ criticizes Price $(2009,326)$ for taking Quine to identify the two. She responds by arguing that Quine's pragmatism is merely epistemological, by which she means that Quine is 'devoted to working within our best theory and improving it from the inside, and embracing porous boundaries between subject areas' $(2014,5)$. So let us suppose that Quine indeed does not identify truth with usefulness. After all, what a theory, suitably regimented, quantifies over really does exist 'from the standpoint of that theory' (Quine, 1960, 21):

Everything to which we concede existence is a posit from the standpoint of a description of the theory building process, and simultaneously real from the standpoint of the theory that is being built. Nor let us look down on the standpoint of the theory as make-believe, for we can never do better than occupy the standpoint of some theory or other, the best we can muster at the time.

This is compatible with recognizing a difference between Quine's conception of ontology (and metaphysics) on the one hand, and the one in play in the contemporary scene, on the other. Being interested in what exists 'from the standpoint' of our best theories is not the same as taking oneself to investigate what the world is like simpliciter. Of course a contemporary Siderean metaphysician need not take her theories, nor the scientific theories with which they are intended to be continuous, to be unrevisable. But her aim is to get ever closer to discerning the fundamental structure of the world. Again, this is a degree of metaphysical seriousness that seems to be absent from the Quinean program. Perhaps unsurprisingly, Quine never explicitly takes a stand on the question that drives contemporary metaphysical theorizing about time, namely whether and in what sense time passes. 


\section{Carnap, Triviality, and Temporal Passage}

Consider again presentism, understood as the view that only the present exists, or only present things exist. As has been pointed out, there are salient readings of this that are trivial ${ }^{6}$ In particular, if 'exists' means exists now, presentists claim that only present things exist now, which is trivially true. Alternatively, if 'exists' means has existed, exists now, or will exist, then the view arguably is trivially false: dinosaurs have existed but are not present. If we want to avoid attributing a trivially false or trivially true view to either side in temporal ontology, this problem (let's call it the 'triviality challenge') suggests that the way to construe presentism, and eternalism, is in terms of existence simpliciter: presentists hold that only present things exist, simpliciter. Eternalists and presentists disagree over what exists simpliciter. They disagree, that is, over whether what exists, full-stop, includes only the present and only present things, or also such things as other times and things at other times, like dinosaurs or Martian outposts. The question of temporal ontology, to borrow a metaphor by Joshua Mozersky $(2011,124)$, is: when the quantifier's wings are stretched as wide as they can be, ready to catch anything that is temporal, are only present things (and only the present time) caught by it? Or also (things from) other times?

Sider's formulation of the debate can be thought of as one attempt to elucidate the metaphor. As we have seen, Quine's approach to eternalism, and to the 'four-dimensional spatio-temporal view of nature', differs from Sider's. Nonetheless, neither of them is likely to find the triviality challenge troubling, in the sense that they would see in it an obstacle to regarding the dispute as substantive.

The situation is somewhat different with Carnap. At first sight, one might think that by Carnapian lights the triviality challenge shows up a problem that is internal to the 'tense framework', in which we allow ourselves only tensed notions of existence. The upshot might then seem to be that the 'tenseless framework' is preferable, since it doesn't suffer from triviality. But keep in mind that what we are being asked to formulate within the triviality challenge is presentism-itself a position within the temporal ontology debate. The reason the trivially true reading 'only present things exist now' is not acceptable is that what we are after is a reading of a substantive ontological claim. Similarly, trivial falsity is a problem for a given reading because we are charitably assuming that neither side is saying something obviously false. What the triviality challenge shows is just that in order for the debate to be understood as intended, it has to be formulated in terms of the existence simpliciter of times/events. Presentism is (roughly) the statement that only present things exist, simpliciter. And at this point Carnap will protest on the basis of his prior commitments. The only meaningful external question we can ask here is a practical one: should we adopt a framework that quantifies over times?

Of course, even Carnap can allow that all candidate frameworks are not equally good for all purposes, for example for the purposes of physics. Suppose we consider the two frameworks suggested by Sider's formulation, namely the framework of first-order predicate logic, versus that of quantified tense logic $7^{7}$ Recall that for Sider, from the dispute over the correct temporal ideology flows a dispute over temporal ontology. For the presentist, $\phi \leftrightarrow N \phi$ ( $\phi$ if and only if it is now the case that $\phi$ ). Thus, for the presentist, it is not the case that there exist dinosaurs $(\exists x D x)$, though it was the case in the past that there exist dinosaurs $(P \exists x D x)$. For Carnap, a particular choice between the two frameworks could be suggested by fit for a given purpose, and/or by views about the relative expressive power of the logics involved. But what is ruled out as meaningless is the question of whether it would be correct to adopt the framework that allows us to quantify over times. In other words, what is ruled out as meaningless is the question of temporal ontology as understood nowadays, about whether all times exist simpliciter.

How does this relate to temporal metaphysics more generally, and in particular, to the question of whether time (robustly) passes? Those seeking to elucidate what is at stake in temporal ontology some-

\footnotetext{
${ }^{6}$ See, e.g., (Meyer 2005, Dorato 2006, Savitt 2006, Stoneham 2009, Lombard 2010, Balaguer 2014, Tallant 2014.)

${ }^{7}$ Admittedly, it is not quite clear how to fit the latter into the mould given by Carnap's description for what constitutes a framework in 'Empiricism, Semantics, and Ontology'. After all, introducing tense operators is not the same as introducing variables of a new type. If the reader prefers, they may construe what follows as being merely about whether or not to adopt the framework of first-order predicate logic.
} 
times try to bracket considerations of temporal passage, taking these to be unnecessarily obscure. It's certainly safe to assume that debates about temporal passage are no more likely to appeal to figures like Carnap, or even Quine, than are debates that focus just on temporal ontology. In fact, what we should say here is that the two are not neatly separable.

Christian Wüthrich disagrees, arguing that passage is no necessary part of presentism. He says that a 'Heraclitean' demand for a dynamic succession of presents is 'simply misplaced qua objection to the substantiality of the debate. ... it may well be the case that any attempt to accommodate animation will be frustrated either by triviality or by incoherence' (Wüthrich 2011,4), but that is not relevant, for presentism is an ontological thesis, 'not an ideological statement about the qualities-dynamical or otherwise - of that which exists' (Wüthrich 2013, 2). But in fact, passage is part and parcel of the view that presentism is intended to be. Take Wüthrich's own interpretation of presentism as the view that only a subset of (the eternalist's) events physically exist. The problem with this is that the presentist explicitly refrains from restricting existence to only a subset of events in the manifold; she is defending a view about what events physically exist, while leaving nothing out. Moreover, this formulation is made all the more puzzling if one insists that presentism has nothing to do with time's passing. Which subset is being posited? 49BC? 1980? A day in 2019? The intended answer, it seems, is that the subset changes as time passes. For better or worse, the question of temporal passage sits at the heart of the contemporary metaphysical debates about time.

It should therefore come as no surprise that philosophers of time with Carnapian sympathies also tend to question the substantiality of the dispute over whether time (robustly) passes. One example of this combination is provided by Steven Savitt's $(2002,2006)$ work on time; similar views are defended, for example, in (Dorato 2006), (Dieks 2006), and (Arthur 2006). Consider again the question of which times exist, simpliciter. Savitt echoes Austin's demand for a contrast class and points out that neither the merely past/future nor the merely fictional/imaginary/possible contrast class provides 'exists' with a suitable meaning. You exist in a sense in which Newton does not. Both of you exist in a sense in which Santa Claus does not. The triviality challenge teaches us not to saddle either side in temporal ontology with a denial of these claims. And it leaves us at a loss for how else to construe the positions (Savitt 2006, Deng 2018). This assessment is Carnapian in spirit, in the sense that Carnap would even maintain that the question of temporal ontology, like other ontological questions, is meaningless. And it is of a piece with Savitt's defense of a minimalist view of passage, according to which time's passing is simply the successive happening of events.

\section{Conclusion}

I have surveyed Quine's and Carnap's metaontological stances, as well as some of Quine's ontological commitments, and I made some suggestions for where each might be situated with respect to the contemporary landscape in the metaphysics of time. The upshot was that contemporary temporal metaphysics is characterized by a degree of metaphysical seriousness that is absent from Quine's program. Similarly, Carnap would not recognize a meaningful question about temporal ontology as this is understood nowadays, namely as a question about whether all times exist simpliciter. Finally, there is a natural affinity between Carnapian approaches to temporal ontology and deflationary attitudes towards the wider metaphysical question of whether time passes.

\section{Acknowledgments}

I would like to thank Frederique Janssen-Lauret, as well as Steven Savitt, for helpful comments on earlier drafts. I would also like to thank Casey McCoy for typesetting and editing assistance. This chapter was 
partly written while I was supported by the Yonsei University Future-Leading Research Initiative 2018 (2018-22-0100).

\section{Bibliography}

Arthur, R.T.W. 2006. 'Minkowski Spacetime and the Dimensions of the Present'. In The Ontology of Spacetime, Volume 1, edited by D. Dieks, pp. 129-155. Amsterdam: Elsevier.

Balaguer, M. 2014. 'Anti-metaphysicalism, Necessity, and Temporal Ontology'. Philosophy and Phenomenological Research 89 (1): 145-167.

Callender, C. 2017. What Makes Time Special? Oxford: Oxford University Press.

Carnap, R. 1950. 'Empiricism, Semantics, and Ontology'. Revue Internationale de Philosophie 4 (11): 20-40.

Carnap, R. 1963. 'Carnap's Intellectual Autobiography'. In The Philosophy of Rudolph Carnap, edited by P. Schilpp, pp. 3-86. La Salle: Open Court.

Deng, N. 2018. 'What is Temporal Ontology?' Philosophical Studies 175 (3): 793-807.

Dieks, D. 2006. 'Becoming, Relativity, and Locality'. In The Ontology of Spacetime, Volume 1, edited by D. Dieks, pp. 157-176. Amsterdam: Elsevier.

Dorato, M. 2006 'The Irrelevance of the Presentist/Eternalist Debate for the Ontology of Minkowski Spacetime'. In The Ontology of Spacetime, Volume 1, edited by D. Dieks, pp. 93-110. Amsterdam: Elsevier.

Hylton, P. 2018. 'Willard van Orman Quine'. In The Stanford Encyclopedia of Philosophy (Summer 2018 Edition), edited by E.N. Zalta. URL = <https://plato.stanford.edu/archives/sum2018/entries/quine/>.

Janssen-Lauret, F. 2015. 'Meta-Ontology, Naturalism, and The Quine-Barcan Marcus Debate'. In Quine and His Place in History, edited by F. Janssen-Lauret and G. Kemp, pp. 146-167. London: PalgraveMacmillan.

Janssen-Lauret, F. 2016. 'Committing to an Individual: Ontological Commitment, Reference and Epistemology’. Synthese 193 (2): 583-604.

Lombard, L. 2010. 'Time for a Change: A Polemic Against the Presentism/Eternalism Debate'. In Time and Identity, edited by J. Campbell, M. O’Rourke, and H. Silverstein, pp. 49-77. Cambridge: MIT Press.

Meyer, U. 2005 'The Presentist's Dilemma'. Philosophical studies 122 (3): 213-225.

Mozersky, J. 2011. 'Presentism'. In The Oxford Handbook of Philosophy of Time, edited by C. Callender, pp. 122-143. Oxford: Oxford University Press.

Price, H. 2009. 'Metaphysics after Carnap: The Ghost Who Walks?' In Metametaphysics, edited by D.J. Chalmers, D. Manley, and R. Wasserman, pp. 320-346. Oxford: Oxford University Press. 
Quine, W. V. O. 1939. 'Designation and Existence'. The Journal of Philosophy 36 (26): 701-709.

Quine, W. V. O. 1948. 'On What There Is'. The Review of Metaphysics 2 (1): 21-38.

Quine, W. V. O. 1950. 'Identity, Ostension, and Hypostasis'. The Journal of Philosophy 47 (22): 621633.

Quine, W. V. O. 1951a. 'Ontology and Ideology'. Philosophical Studies 2 (1): 11-15.

Quine, W. V. O. 1951b. 'On Carnap's Views on Ontology'. Philosophical Studies 2 (5): 65-72.

Quine, W. V. O. 1953. 'Mr. Strawson on Logical Theory’. Mind 62 (248): 433-451.

Quine, W. V. O. 1960. Word and Object. Cambridge: MIT Press.

Quine, W. V. O. 1981. 'Things and Their Place in Theories'. In Theories and Things, pp. 1-23. Cambridge: Harvard University Press.

Savitt, S. 2002. 'On Absolute Becoming and the Myth of Passage'. Royal Institute of Philosophy Supplement 50: 153-167.

Savitt, S. 2006. 'Presentism and Eternalism in Perspective'. In The Ontology of Spacetime, Volume 1, edited by D. Dieks, pp. 111-128. Amsterdam: Elsevier.

Sider, T., 2011. Writing the Book of the World. Oxford: Oxford University Press.

Stoneham, T. 2009. 'Time and Truth: The Presentism-Eternalism Debate'. Philosophy 84 (2): 201-218.

Strawson, P. F. 1952. Introduction to Logical Theory. London: Methuen.

Tallant, J. 2014. 'Defining Existence Presentism'. Erkenntnis 79 (3): 479-501.

Wüthrich, C. 2011. 'Demarcating Presentism'. In EPSA Philosophy of Science: Amsterdam 2009, edited by H. De Regt, S. Okasha, and S. Hartmann, pp. 441-450. Dordrecht: Springer.

Wüthrich, C. 2013 'The Fate of Presentism in Modern Physics'. In New Papers on the Present, edited by R. Ciuni, K. Miller, and G. Torrengo, pp. 91-132. Munich: Philosophia. 